Pacific Journal of Mathematic 


\title{
STABILITY OF MEASURE DIFFERENTIAL EQUATIONS
}

\author{
S. LEELA
}

The preservation of stability properties of perturbed differential equations when the perturbations are impulsive are discussed relative to asymptotically self invariant sets. The fact that the solutions of perturbed systems are discontinuous offers many difficulties in applying the usual methods of perturbation theory and thus makes the study interesting.

1. Introduction. Generally, in perturbation theory, we consider the perturbed system given by

$$
\frac{d x}{d t}=f(t, x)+R(t, x),
$$

where the perturbation term $R(t, x)$ is continuous and small in some sense. But it is of much importance to consider the case when the perturbation term is rather wildly impulsive in character and it is also natural to expect such a situation in pulse frequency modulation systems, models for biological neural nets and some automatic control problems. Thus the study of equations of the type

$$
D X=f(t, x)+G(t, x) D u,
$$

where $D u$ denotes the distributional derivative of the function $u$ is important in itself. Equations of the form (1.1) are called measure differential equations. The existence of solutions of such equations has been studied by Schmaedeke, W. W. [6] and Das, P. C. and Sharma, R. R., (see [2], [3]).

Our interest here is to treat Eq. (1.1) as a perturbation of the ordinary differential system

$$
\frac{d x}{d t}=f(t, x)
$$

and to investigate the preservation of stability properties of solutions of (1.2) under the effect of impulsive perturbations. Some simple situations of the stability of such problems have been considered by Das, P. C. and Sharma, R. R. [3], Barbashin, E. A.[1] and Zabalishchin, S. T. [7].

The fact that the solutions of (1.1) are discontinuous (i.e., functions of bounded variation) offers many difficulties in applying the usual techniques of perturbation theory. It is known (see [4], [5]) that even in the case of ordinary differential systems, it is more general and natural to consider the stability of asymptotically self 
invariant (ASI) sets rather than that of usual invariant sets. Thus, it seems more appropriate to consider ASI sets and their stability properties with respect to (1.1). In this paper, we study the effect of impulsive perturbations on the stability in variation of ASI sets, making use of the methods developed in our earlier work [5].

2. Notation and basic theorems. Let $R^{n}$ and $M$ denote the $n$ Euclidean space and the set of all $n \times m$ matrices of real numbers, with the norms $\|x\|=\sum_{i=1}^{n}\left|x_{i}\right|, x \in R^{n}$ and $\|G\|=\sum_{i=1}^{n} \sum_{j=1}^{m}\left|g_{i j}\right|,\left(g_{i j}\right)=$ $G \in M$, respectively. Let $B v\left(R^{+}, R^{m}\right)$ denote the set of all vector functions defined on $R^{+}$with values in $R^{m}$, whose components are scalar functions of bounded variation on $R^{+}$.

Let us consider the measure differential equation

$$
D x=f(t, x)+G(t, x) D u, \quad x\left(t_{0}\right)=x_{0}, t_{0} \geqq 0,
$$

where (i) the functions $f$ and $G$ are defined on $R^{+} \times S(\rho), S(\rho)=$ [ $x \in R^{n}:\|x\|<\rho$ ], with values in $R^{n}$ and $M$ respectively; (ii) $u$ is a right continuous function belonging to the set $B v\left(R^{+}, R^{m}\right)$; and (iii) $D x, D u$ denote the distributional derivatives of functions $x$ and $u$ (identified with Stieltjes measure) respectively.

Definition 1. A function $y(\cdot)=y\left(\cdot, t_{0}, x_{0}\right)$ is said to be a solution of Eq. (2.1) on $R^{+}$if $y(\cdot)$ is a right continuous function $\in B v\left(R^{+}, S(\rho)\right)$ and the distributional derivative of $y(\cdot)$ on $\left(t_{0}, T\right), T \in R^{+}$, satisfies the Eq. (2.1).

For the existence and uniqueness of solutions of Eq. (2.1) and for more details about equations of the type (2.1), refer [2], [3]. In the sequel, we shall assume that the solutions of Eq. (2.1) exist and are unique for $t \geqq t_{0}$.

The following classes of functions will be used often in our discussion. So, we define

$L=\left[\sigma: \sigma \in C\left[R^{+}, R^{+}\right], \quad \sigma(t)\right.$ is decreasing in $t$ and $\sigma(t) \rightarrow 0$ as $\left.t \rightarrow \infty\right]$; $A=\left[a: a \in C\left[R^{+} x[0, \rho), R^{+}\right], a(t, r)\right.$ is decreasing in $t$ for each $r$ and increasing in $r$ for each $t$ such that $\left.\lim _{\substack{t \rightarrow \infty \\ r \rightarrow 0}} a(t, r)=0\right]$;

$$
\begin{aligned}
B= & {\left[H: H \in C\left[R^{+} x R^{+}, R^{+}\right] \text {and for some } \tau>0,\right.} \\
& \left.\lim _{t \rightarrow \infty}\left\{\begin{array}{l}
\sup H\left(t, t_{0}\right) \\
t_{0} \geqq \tau
\end{array}\right\}=0\right],
\end{aligned}
$$

where $C[Y, Z]$ denote the set of continuous functions on $Y$ taking values in $Z$.

We shall now suppose that $f \in C\left[R^{+} x S(\rho), R^{n}\right], f_{x}(t, x)$ exists and 
is continuous on $R^{+} x S(\rho)$ and $x\left(t, t_{0}, x_{0}\right)$ is the solution of the unperturbed system

$$
\frac{d x}{d t}=f(t, x), \quad x\left(t_{0}\right)=x_{0} .
$$

Let $\Phi\left(t, t_{0}, x_{0}\right)$ denote the fundamental matrix solution of the variational system

$$
\frac{d z}{d t}=f_{x}\left(t, x\left(t, t_{0}, x_{0}\right)\right) z, \quad z\left(t_{0}\right)=1 \text { (identity matrix) } .
$$

We use the following definitions for the characterization of the asymptotically self invariant (ASI) set with respect to the system (2.2) and the stability criteria of such sets.

DEFINITION 2. The set $x=0$ is said to be ASI relative to (2.2) if every solution $x\left(t, t_{0}, 0\right)$ of $(2.2)$ satisfies

$$
\left\|x\left(t, t_{0}, 0\right)\right\| \leqq \lambda\left(t_{0}\right), t \geqq t_{0}, \lambda \in L .
$$

Definition 3. The ASI set $x=0$ is said to be

(i) uniformly stable in variation, if for each $\alpha, 0<\alpha \leqq \rho$, there exists a constant $M(\alpha)>0$ such that

$$
\left\|\Phi\left(t, t_{0}, x_{0}\right)\right\| \leqq M(\alpha), \quad t \geqq t_{0},
$$

provided $\left\|x_{0}\right\| \leqq \alpha$

(ii) uniformly asymptotically stable in variation, if for each $\alpha, 0<\alpha \leqq \rho$, there exists a function $\sigma_{\alpha} \in L$ such that whenever $\left\|x_{0}\right\| \leqq \alpha$,

$$
\left\|\Phi\left(t, t_{0}, x_{0}\right)\right\| \leqq \sigma_{\alpha}\left(t-t_{0}\right), \quad t \geqq t_{0} ;
$$

(iii) uniformly stable, if there exists a function $a \in A$ such that

$$
\left\|x\left(t, t_{0}, x_{0}\right)\right\| \leqq a\left(t_{0},\left\|x_{0}\right\|\right), \quad t \geqq t_{0} ;
$$

(iv) uniformly asymptotically stable, if there exist functions $a \in A, \eta \in L$, and $H \in B$ such that

$$
\left\|x\left(t, t_{0}, x_{0}\right)\right\| \leqq a\left(t_{0},\left\|x_{0}\right\|\right) \eta\left(t-t_{0}\right)+H\left(t, t_{0}\right), \quad t \geqq t_{0} ;
$$

(v) quasi-equi asymptotically stable if the estimate in (iv) is replaced by

$$
\left\|x\left(t, t_{0}, x_{0}\right)\right\| \leqq\left\{a\left(t_{0},\left\|x_{0}\right\|\right)+\beta\right\} \eta\left(t-t_{0}\right)+H\left(t, t_{0}\right), t \geqq t_{0},
$$

where $\beta$ is a constant $>0$ and the functions $a, \eta$, and $H$ are as in (iv);

(vi) exponentially asymptotically stable if, for $t \geqq t_{0}$, 


$$
\left\|x\left(t, t_{0}, x_{0}\right)\right\| \leqq\left\{a\left(t_{0},\left\|x_{0}\right\|\right)+\beta\right\} e^{-\tilde{\delta}\left(t-t_{0}\right)}+H\left(t, t_{0}\right),
$$

where the constant $\beta \geqq 0, \delta>0, a \in A$ and $H \in B$.

REMARK. If $f(t, 0) \equiv 0$ so that $x \equiv 0$ is the unique solution of (2.2), then the ASI set reduces to the usual invariant set.

We next state two known results [5] which are very useful in our investigation of stability properties of Eq. (2.1).

Theorem 2.1. Assume that the ASI set $x=0$ with respect to (2.2) is uniformly stable in variation. Then, there exists a Lyapunov function $V(t, x)$ with the following properties:

(1) $V(t, x)$ is defined and continuous on $R^{+} \times S(\alpha)$;

(2) $\|x\| \leqq V(t, x) \leqq \alpha(t,\|x\|),(t, x) \in R^{+} \times S(\alpha), a \in A$;

(3) $|V(t, x)-V(t, y)| \leqq M(\alpha)\|x-y\|,(t, x),(t, y) \in R^{+} \times S(\alpha)$;

(4) $D^{+} V_{(2.2)}(t, x)=\lim _{h \rightarrow 0^{+}} \sup 1 / h[V(t+h, x+h f(t, x))-V(t, x)] \leqq$ 0 , for $(t, x) \in R^{+} \times S(\alpha)$.

THEOREM 2.2. Suppose that the ASI set $x=0$ relative to (2.2) is uniformly asymptotically stable in variation. Then, there exists a Lyapunov function $W(t, x)$ verifying the following properties:

(1') $W(t, x)$ is defined and continuous on $R^{+} \times S(\alpha)$;

(2') $\|x\| \leqq W(t, x) \leqq b(t,\|x\|),(t, x) \in R^{+} \times S(\alpha), b \in A$;

(3) $|W(t, x)-W(t, y)| \leqq L(\alpha)\|x-y\|,(t, x),(t, y) \in R^{+} \times S(\alpha)$;

( $\left.4^{\prime}\right) \quad D^{+} W_{(2.2)}(t, x) \leqq-\delta W(t, x)+\lambda(t),(t, x) \in R^{+} \times S(\alpha)$, where $\delta>0$ and $\lambda \in L$.

REMARK. It is important to note that the Lyapunov functions obtained in the foregoing theorems are Lipschitzian in $x$ for a constant and this fact plays a crucial role in studying the effect of perturbations. The usefulness of the stability in variation notions lies in the above fact.

3. Main results. In this section, we shall assume that the set $x=0$ is ASI relative to the unperturbed system (2.2) and give sufficient conditions for the stability criteria of the ASI set $x=0$ with respect to the measure differential system (2.1). First we state the following hypotheses:

$\left(\mathrm{H}_{1}\right) \quad f(t, x)$ and $f_{x}(t, x)$ are defined and continuous on $R^{+} \times S(\rho)$ and $f_{x}(t, x)$ is bounded on $R^{+} \times S(\rho)$;

$\left(\mathrm{H}_{2}\right)$ the ASI set $x=0$ relative to (2.2) is uniformly stable in variation;

$\left(\mathrm{H}_{3}\right)$ the ASI set $x=0$ relative to (2.2) is uniformly asymptotically stable in variation; 
$\left(\mathrm{H}_{4}\right) \quad\|G(t, x)\| \leqq g(t)\|x\|$ on $R^{+} \times S(\rho)$ where $G(t, x)$ is measurable in $t$ for each $x$, continuous in $x$ for each $t$ and $g(t)$ is $d v_{u}$ integrable function $v_{u}$ being the total variation function of $u$;

$\left(\mathrm{H}_{5}\right) \quad \int_{0}^{\infty} w(s) d s<\infty$ where

$$
w(t)=\lim _{h \rightarrow 0^{+}} \sup \frac{1}{h} \int_{t}^{t+h} g(s) d v_{u}(s)
$$

is the upper right Dini derivative of the indefinite integral $\int^{t} g(s) d v_{u}(s)$;

$\left(\mathrm{H}_{6}\right)$ the function $w(t)$ in $\mathrm{H}_{5}$ is such that

$$
\int_{t}^{t+1} w(s) d s \longrightarrow 0 \text { as } t \longrightarrow \infty ;
$$

$\left(\mathrm{H}_{7}\right)$ the discontinuities of $u$ occur at isolated points $\left\{t_{k}\right\}, t_{1}<$ $t_{2}<\cdots<t_{k}<\cdots$ and are such that

$$
\left\|u\left(t_{k}\right)-u\left(t_{k}^{-}\right)\right\| \leqq \lambda_{k} \exp \left(\int_{t_{0}}^{t_{k}} w(s) d s\right), k=1,2, \cdots,
$$

and $\lambda_{k}$ are constants ;

$\left(\mathrm{H}_{8}\right) \quad \sum_{k=1}^{\infty} g\left(t_{k}\right) \lambda_{k}$ converges.

We are now in a position to state our first main result which deals with the sufficient conditions for the uniform stability of the ASI set $x=0$ with respect to the perturbed system (2.1).

THEOREM 3.1. Assume that the hypotheses $\left(\mathrm{H}_{1}\right),\left(\mathrm{H}_{2}\right),\left(\mathrm{H}_{4}\right),\left(\mathrm{H}_{5}\right)$, $\left(\mathrm{H}_{7}\right)$, and $\left(\mathrm{H}_{8}\right)$ are satisfied. Then, the set $x=0$ is ASI with respect to (2.1) and is uniformly stable.

Naturally, the proof depends on the construction of a Lyapunov function for the unperturbed system (2.2), obtaining the estimate of solutions of the perturbed system (2.1) in terms of that Lyapunov function and estimating the jumps of the solutions of (2.1) at the points of discontinuity. For convenience, we first state and prove the following lemmas. Then,

LeMmA 3.1. Let the hypotheses $\left(\mathrm{H}_{1}\right),\left(\mathrm{H}_{2}\right),\left(\mathrm{H}_{4}\right)$, and $\left(\mathrm{H}_{5}\right)$ hold.

$$
\left\{\begin{aligned}
D^{+} m(t) & =\lim _{h \rightarrow 0^{+}} \sup \frac{1}{h}[m(t+h)-m(t)] \\
& \leqq M(\alpha)\left\|y\left(t, t_{0}, x_{0}\right)\right\| w(t)+\underset{(2.2)}{D^{+} V(t, x),}
\end{aligned}\right.
$$

where $m(t)=V\left(t, y\left(t, t_{0}, x_{0}\right)\right), y\left(t, t_{0}, x_{0}\right)$ is the solution of $(2.1), V(t, x)$ 
is the Lyapunov function obtained in Theorem 2.1 and $M(\alpha)$ is the Lipschitz constant for the function $V(t, x)$.

Proof. Set $x=y\left(t, t_{0}, x_{0}\right)$ and note that $y\left(t+h, t_{0}, x_{0}\right) \equiv y(t+h, t, x)$, $h>0$, in view of the assumed uniqueness of solutions of (2.1). Also, let $x(s, t, x)$ denote the solution of the system (2.2). Then, using the definition of $m(t)$, the Lipschitzian property of $V$, we get,

$$
\begin{aligned}
D^{+} m(t)= & \lim _{h \rightarrow 0^{+}} \sup \frac{1}{h}\left[V\left(t+h, y\left(t+h, t_{0}, x_{0}\right)\right)-V\left(t, y\left(t, t_{0}, x_{0}\right)\right)\right] \\
= & \lim _{h \rightarrow 0^{+}} \sup \frac{1}{h}[V(t+h, y(t+h, t, x))-V(t, x)] \\
\leqq & \lim _{h \rightarrow 0^{+}} \sup \frac{1}{h}[V(t+h, y(t+h, t, x))-V(t+h, x(t+h, t, x))] \\
& +\lim _{h \rightarrow 0^{+}} \sup \frac{1}{h}[V(t+h, x(t+h, t, x))-V(t+h, x+h f(t, x))] \\
& +\lim _{h \rightarrow 0^{+}} \sup \frac{1}{h}[V(t+h, x+h f(t, x))-V(t, x)] \\
\leqq & M(\alpha) \lim _{h \rightarrow 0^{+}} \sup \left[\frac{1}{h}\|y(t+h, t, x)-x(t+h, t, x)\|\right]+D_{(2.2)}^{+} V(t, x) \\
\leqq & M(\alpha) \lim _{h \rightarrow 0^{+}} \sup \frac{1}{h}\left\{\int_{t}^{t+h}\|f(s, y(s, t, x))-f(s, x(s, t, x))\| d s\right. \\
& \left.+\int_{t}^{t+h}\|G(s, y(s, t, x))\| d v_{u}(s)\right\}+\underset{(2.2)}{D^{+} V(t, x),}
\end{aligned}
$$

where $v_{u}$ is the total variation function of $u$.

Since $f$ is Lipschitzian in $x$,

$$
\begin{gathered}
\lim _{h \rightarrow 0^{+}} \sup \frac{1}{h}\left[\int_{t}^{t+h}\|f(s, y(s, t, x))-f(s, x(s, t, x))\| d s\right] \\
\leqq L \lim _{h \rightarrow 0^{+}} \sup \left[\sup _{t \leqq s \leqq t+h}(\|y(s, t, x)-x(s, t, x)\|)\right]=0,
\end{gathered}
$$

and we obtain, using $\left(\mathrm{H}_{4}\right), D^{+} m(t) \leqq M(\alpha) w(t)\left\|y\left(t, t_{0}, x_{0}\right)\right\|+D^{+} V_{(2.2)}(t, x)$.

LEMmA 3.2. Let the hypotheses $\left(\mathrm{H}_{1}\right),\left(\mathrm{H}_{2}\right),\left(\mathrm{H}_{4}\right)$, and $\left(\mathrm{H}_{5}\right)$ hold. If $y\left(t, t_{0}, x_{0}\right)$ is a solution of (2.1), then, at the points of discontinuity $\left\{t_{k}\right\}$, we have

$$
\left\{\begin{array}{c}
\left|V\left(t_{k}, y\left(t_{k}, t_{0}, x_{0}\right)\right)-V\left(t_{k}, y\left(t_{k}^{-}, t_{0}, x_{0}\right)\right)\right| \\
\leqq M(\alpha) \rho g\left(t_{k}\right)\left\|u\left(t_{k}\right)-u\left(t_{k}^{-}\right)\right\|
\end{array}\right.
$$

Proof. Following the arguments in [3], we get 


$$
\left\|y\left(t_{k}, t_{0}, x_{0}\right)-y\left(t_{k}^{-}, t_{0}, x_{0}\right)\right\|=\left\|G\left(t_{k}, y\left(t_{k}, t_{0}, x_{0}\right)\right)\left[u\left(t_{k}\right)-u\left(t_{k}^{-}\right)\right]\right\| .
$$

Hence, using the assumption $\left(\mathrm{H}_{4}\right)$,

$$
\begin{aligned}
& \left|V\left(t_{k}, y\left(t_{k}, t_{0}, x_{0}\right)\right)-V\left(t_{k}, y\left(t_{k}^{-}, t_{0}, x_{0}\right)\right)\right| \\
& \quad \leqq M(\alpha)\left\|y\left(t_{k}, t_{0}, x_{0}\right)-y\left(t_{k}^{-}, t_{0}, x_{0}\right)\right\| \\
& \quad \leqq M(\alpha) g\left(t_{k}\right)\left\|y\left(t_{k}, t_{0}, x_{0}\right)\right\|\left\|u\left(t_{k}\right)-u\left(t_{k}^{-}\right)\right\|,
\end{aligned}
$$

which yields the estimate (3.3).

Proof of Theorem 3.1. Recalling that $D^{+} V_{(2.2)}(t, x) \leqq 0$ and $\|x\| \leqq$ $V(t, x)$, we have from (3.2), the following differential inequality

$$
D^{+} m(t) \leqq M(\alpha) m(t) w(t) .
$$

Since $y\left(t, t_{0}, x_{0}\right)$ is continuous on $\left[t_{k-1}, t_{k}\right), k=1,2, \cdots$, the inequality (3.4) yields, for each $t \in\left[t_{k-1}, t_{k}\right)$,

$$
V\left(t, y\left(t, t_{0}, x_{0}\right)\right) \leqq V\left(t_{k-1}, y\left(t_{k-1}, t_{0}, x_{0}\right)\right) \exp \left(M(\alpha) \int_{t_{k-1}}^{t} w(s) d s\right) .
$$

In view of (3.3), (3.5), and (3.1), we now obtain

$$
\begin{aligned}
& V\left(t_{k}, y\left(t_{k}, t_{0}, x_{0}\right)\right) \\
& \leqq V\left(t_{k}, y\left(t_{k}^{-}, t_{0}, x_{0}\right)\right)+M(\alpha) \rho g\left(t_{k}\right) \lambda_{k} \exp \left(M(\alpha) \int_{t_{0}}^{t_{k}} w(s) d s\right) \\
& \leqq V\left(t_{k-1}, y\left(t_{k-1}, t_{0}, x_{0}\right)\right) \exp \left(M(\alpha) \int_{t_{k-1}}^{t_{k}} w(s) d s\right) \\
&+M(\alpha) \rho g\left(t_{k}\right) \lambda_{k} \exp \left(M(\alpha) \int_{t_{0}}^{t_{k}} w(s) d s\right),
\end{aligned}
$$

where $M(\alpha) \geqq 1$ (without any loss of generality).

Also, we have

$$
\begin{aligned}
& V\left(t, y\left(t, t_{0}, x_{0}\right)\right) \leqq V\left(t_{0}, x_{0}\right) \exp \left(M(\alpha) \int_{t_{0}}^{t} w(s) d s\right), t \in\left[t_{0}, t_{1}\right) \\
& V\left(t, y\left(t, t_{0}, x_{0}\right)\right) \leqq V\left(t_{1}, y\left(t_{1}, t_{0}, x_{0}\right)\right) \exp \left(M(\alpha) \int_{t_{1}}^{t} w(s) d s\right), t \in\left[t_{1}, t_{2}\right) .
\end{aligned}
$$

Hence, for $t \in\left[t_{0}, t_{2}\right)$ we get

$$
\begin{aligned}
& V\left(t, y\left(t, t_{0}, x_{0}\right)\right) \leqq\left[V\left(t_{0}, x_{0}\right) \exp \left(M(\alpha) \int_{t_{0}}^{t_{1}} w(s) d s\right)\right. \\
& \quad+M(\alpha) \rho g\left(t_{1}\right) \lambda_{1} \exp \left(\left(M(\alpha) \int_{t_{0}}^{t_{1}} w(s) d s\right)\right] \exp \left(M(\alpha) \int_{t 1}^{t} w(s) d s\right) \\
& =\left[V\left(t_{0}, x_{0}\right)+M(\alpha) \rho g\left(t_{1}\right) \lambda_{1}\right] \exp \left(M(\alpha) \int_{t_{0}}^{t} w(s) d s\right) .
\end{aligned}
$$

Thus, in general, for $t \geqq t_{0}$, 


$$
V\left(t, y\left(t, t_{0}, x_{0}\right)\right) \leqq\left[V\left(t_{0}, x_{0}\right)+M(\alpha) \rho \sum_{k=1}^{\infty} g\left(t_{k}\right) \lambda_{k}\right] \exp \left(M(\alpha) \int_{t_{0}}^{t} w(s) d s\right) .
$$

Now, using the upper and lower estimates of $V$ (see Theorem 2.1), we get

$$
\left\|y\left(t, t_{0}, x_{0}\right)\right\| \leqq\left[a\left(t_{0},\left\|x_{0}\right\|\right)+M(\alpha) \rho \sum_{k=1}^{\infty} g\left(t_{k}\right) \lambda_{k}\right] N\left(t_{0}\right) \equiv \hat{a}\left(t_{0},\left\|x_{0}\right\|\right),
$$

where $N\left(t_{0}\right)=\exp \left(M(\alpha) \int_{t_{0}}^{\infty} w(s) d s\right)$. Clearly $\hat{a} \in A$ since $\sum_{k=1}^{\infty} g\left(t_{k}\right) \lambda_{k}$ converges and the proof is complete.

THEOREM 3.2. Let the hypotheses $\left(\mathrm{H}_{1}\right),\left(\mathrm{H}_{3}\right),\left(\mathrm{H}_{4}\right),\left(\mathrm{H}_{6}\right)$, and $\left(\mathrm{H}_{8}\right)$ hold. Further, let

$$
\left\|u\left(t_{k}\right)-u\left(t_{k}^{-}\right)\right\| \leqq \lambda_{k} \exp \left(-\delta\left(t_{k}-t_{0}\right)\right), \quad \delta>0,
$$

be satisfied in place of (3.1) in $\left(\mathrm{H}_{7}\right)$. Then, the ASI set $x=0$ is exponentially asymptotically stable with respect to (2.1).

Proof. We now employ the Theorem 2.2 and set $m(t)=$ $W\left(t, y\left(t, t_{0}, x_{0}\right)\right)$, where $W(t, x)$ is the Lyapunov function obtained in Theorem 2.2. Using the same arguments as in proof of Lemma 3.1 for this $W$, we get, in place of (3.2), the following inequality:

$$
\left\{\begin{aligned}
D^{+} m(t) & \leqq L(\alpha) \rho w(t)+D_{(2 \cdot 2)}^{+} W(t, x) \\
& \leqq L(\alpha) \rho w(t)+\lambda(t)-\delta m(t) \\
& =\lambda_{0}(t)-\delta m(t), \quad \delta>0
\end{aligned}\right.
$$

with $\lambda_{0}(t)=L(\alpha) \rho w(t)+\lambda(t)$. Obviously, $\int_{t}^{t+1} \lambda_{0}(s) d s \rightarrow 0$ as $t \rightarrow \infty$. Since $y\left(t, t_{0}, x_{0}\right)$ is continuous on $\left[t_{k-1}, t_{k}\right), k=1,2, \cdots$, the differential inequality (3.7) implies, for each $t \in\left[t_{k-1}, t_{k}\right.$ ),

$$
\left\{\begin{aligned}
W\left(t, y\left(t, t_{0}, x_{0}\right)\right) & \leqq W\left(t_{k-1}, y\left(t_{k-1}, t_{0}, x_{0}\right)\right) \exp \left(-\delta\left(t-t_{k-1}\right)\right) \\
& +H\left(t, t_{k-1}\right)
\end{aligned}\right.
$$

where $v\left(t, t_{0}, v_{0}\right)=v_{0} \exp \left(-\delta\left(t-t_{0}\right)\right)+H\left(t, t_{0}\right)$ is the solution of the scalar differential equation

$$
v^{\prime}=-\delta v+\lambda_{0}(t), \quad v\left(t_{0}\right)=v_{0},
$$

and $H\left(t, t_{0}\right) \equiv \int_{t_{0}}^{t} \exp (-\delta(t-s)) \lambda_{0}(s) d s$. For the properties $H\left(t, t_{0}\right)$, see [4] and [5].

In view of (3.3) (which is true with $W$ in place of $V$ and $L(\alpha)$ instead of $M(\alpha)),(3.8)$ and the estimate (3.6) for the jumps of $u$, we get 


$$
\begin{aligned}
W\left(t_{k}, y\left(t_{k}, t_{0}, x_{0}\right)\right) \leqq & W\left(t_{k}, y\left(t_{k}^{-}, t_{0}, x_{0}\right)\right)+L(\alpha) \rho g\left(t_{k}\right)\left\|u\left(t_{k}\right)-u\left(t_{k}^{-}\right)\right\| \\
\leqq & W\left(t_{k-1}, y\left(t_{k-1}, t_{0}, x_{0}\right)\right) \exp \left(-\delta\left(t_{k}-t_{k-1}\right)\right) \\
& +H\left(t_{k}, t_{k-1}\right)+L(\alpha) \rho g\left(t_{k}\right) \lambda_{k} \exp \left(-\delta\left(t_{k}-t_{0}\right)\right)
\end{aligned}
$$

We also have

$$
\begin{aligned}
& W\left(t, y\left(t, t_{0}, x_{0}\right)\right) \leqq W\left(t_{0}, x_{0}\right) \exp \left(-\delta\left(t-t_{0}\right)\right)+H\left(t, t_{0}\right), t \in\left[t_{0}, t_{1}\right) ; \\
& W\left(t, y\left(t, t_{0}, x_{0}\right)\right) \leqq W\left(t_{1}, y\left(t_{1}, t_{0}, x_{0}\right)\right) \exp \left(-\delta\left(t-t_{1}\right)\right)+H\left(t, t_{1}\right), t \in\left[t_{1}, t_{2}\right) .
\end{aligned}
$$

Thus, for $t \in\left[t_{0}, t_{2}\right)$, we obtain

$$
\begin{aligned}
W\left(t, y\left(t, t_{0}, x_{0}\right)\right) \leqq & \left\{\left[W\left(t_{0}, x_{0}\right)+L(\alpha) \rho g\left(t_{1}\right) \lambda_{1}\right] \exp \left(-\delta\left(t_{1}-t_{0}\right)\right)\right. \\
& \left.+H\left(t_{1}, t_{0}\right)\right\} \exp \left(-\delta\left(t-t_{1}\right)\right)+H\left(t, t_{1}\right) \\
= & {\left[L(\alpha) \rho g\left(t_{1}\right) \lambda_{1}+W\left(t_{0}, x_{0}\right)\right] \exp \left(-\delta\left(t-t_{0}\right)\right)+H\left(t, t_{0}\right), }
\end{aligned}
$$

since, by the definition of $H\left(t, t_{0}\right)$, it is obvious that

$$
H\left(t_{1}, t_{0}\right) \exp \left(-\delta\left(t-t_{1}\right)\right)+H\left(t, t_{1}\right) \equiv H\left(t, t_{0}\right) .
$$

Hence, in general, it can be shown that, for $t \geqq t_{0}$,

$$
\begin{aligned}
& W\left(t, y\left(t, t_{0}, x_{0}\right)\right) \\
& \quad \leqq\left[W\left(t_{0}, x_{0}\right)+L(\alpha) \rho \sum_{k=1}^{\infty} g\left(t_{k}\right) \lambda_{k}\right] \exp \left(-\delta\left(t-t_{0}\right)\right)+H\left(t, t_{0}\right) .
\end{aligned}
$$

Now, by using the upper and lower estimates of $W(t, x)$ (see Theorem 2.2), we have

$$
\left\|y\left(t, t_{0}, x_{0}\right)\right\| \leqq\left[b\left(t_{0},\left\|x_{0}\right\|\right)+\beta\right] \exp \left(-\delta\left(t-t_{0}\right)\right)+H\left(t, t_{0}\right),
$$

where $\beta=L(\alpha) \rho \sum_{k=1}^{\infty} g\left(t_{k}\right) \lambda_{k}$. Further, using the facts that

(i) $\lim _{t \rightarrow \infty}\left[\sup _{t_{0} \geqq 1} H\left(t, t_{0}\right)\right]=0$ (see [4], p. 113),

(ii) $H\left(t, t_{0}\right) \leqq \sigma\left(t_{0}\right), \sigma \in L$ (see [4]) and

(iii) $\beta$ can be made small by choosing $k$ sufficiently large, we see that the set $x=0$ is ASI relative to the perturbed system (2.1) and that the ASI set $x=0$ is exponentially asymptotically stable with respect to (2.1). The proof is complete.

REMARK. If in the above proof, we do not take $t_{0} \geqq T_{k}$ ( $k$ sufficiently large enough to make $\beta$ as small as we wish), we could still conclude that the solutions of (2.1) tend to zero as $t \rightarrow \infty$, without the ASI set $x=0$ being uniformly stable, i.e., we can conclude that the ASI set is quasi-equi asymptotically stable.

\section{REFERENCES}

1. E. A. Barbashin, On stability with respect to impulsive perturbations, Diff. Uravn.

2, No. 7 (1966), 863-871. 
2. P.C. Das and R. R. Sharma, On optimal controls for measure delay differential equations, J. SIAM Control, 9 (1971), 43-61.

3. - Existence and stability of measure differential equations, Czech. Math. J., 22 (97), (1972), 145-158.

4. V. Lakshmikantham and S. Lecla, Differential and Integral Inequalities, Vol. 1, Academic Press, N. Y., 1969.

5. S. Leela, Asymptotically self invariant sets and perturbed systems, Annali Di Matematica pura ed applicata, No. 4, Vol. XCII (1972), 85-93.

6. W. W. Schmaedeke, Optimal control theory for nonlinear vector differential equations, containing measures, J. SIAM Control, 3 (1965), 231-280.

7. S. T. Zabalishchin, Stability of generalized processes, Diff. Uravn. 2, No. 7 (1966), 872-881.

Received July 29, 1974.

State University College-Geneseo 


\section{PACIFIC JOURNAL OF MATHEMATICS}

\section{EDITORS}

RICHARD ARENS (Managing Editor)

University of California

Los Angeles, California 90024

\section{R. A. Beaumont \\ University of Washington \\ Seattle, Washington 98105}

\section{J. DugundJI}

Department of Mathematics

University of Southern California

Los Angeles, California 90007

D. Gilbarg and J. Milgram

Stanford University

Stanford, California 94305

\section{ASSOCIATE EDITORS}
E. F. BECKENBACH
B. H. NeumanN
F. WOLF
K. YOSHIDA

\section{SUPPORTING INSTITUTIONS}

UNIVERSITY OF BRITISH COLUMBIA
CALIFORNIA INSTITUTE OF TECHNOLOGY
UNIVERSITY OF CALIFORNIA
MONTANA STATE UNIVERSITY
UNIVERSITY OF NEVADA
NEW MEXICO STATE UNIVERSITY
OREGON STATE UNIVERSITY
UNIVERSITY OF OREGON
OSAKA UNIVERSITY

UNIVERSITY OF BRITISH COLUMBIA

UNIVERSITY OF CALIFORNIA

MONTANA STATE UNIVERSITY

NEW MEXICO STATE UNIVERSITY

OREGON STATE UNIVERSITY

OSAKA UNIVERSITY

\author{
UNIVERSITY OF SOUTHERN CALIFORNIA \\ STANFORD UNIVERSITY \\ UNIVERSITY OF TOKYO \\ UNIVERSITY OF UTAH \\ WASHINGTON STATE UNIVERSITY \\ UNIVERSITY OF WASHINGTON \\ AMERICAN MATHEMATICAL SOCIETY \\ NAVAL WEAPONS CENTER
}

The Supporting Institutions listed above contribute to the cost of publication of this Journal, but they are not owners or publishers and have no responsibility for its content or policies.

Mathematical papers intended for publication in the Pacific Journal of Mathematics should be in typed form or offset-reproduced, (not dittoed), double spaced with large margins. Underline Greek letters in red, German in green, and script in blue. The first paragraph or two must be capable of being used separately as a synopsis of the entire paper. Items of the bibliography should not be cited there unless absolutely necessary, in which case they must be identified by author and Journal, rather than by item number. Manuscripts, in triplicate, may be sent to any one of the editors. Please classify according to the scheme of Math. Reviews, Index to Vol. 39. All other communications should be addressed to the managing editor, or Elaine Barth, University of California, Los Angeles, California, 90024.

The Pacific Journal of Mathematics expects the author's institution to pay page charges, and reserves the right to delay publication for nonpayment of charges in case of financial emergency.

100 reprints are provided free for each article, only if page charges have been substantially paid. Additional copies may be obtained at cost in multiples of 50 .

The Pacific Journal of Mathematics is issued monthly as of January 1966. Regular subscription rate: $\$ 72.00$ a year (6 Vols., 12 issues). Special rate: $\$ 36.00$ a year to individual members of supporting institutions.

Subscriptions, orders for back numbers, and changes of address should be sent to Pacific Journal of Mathematics, 103 Highland Boulevard, Berkeley, California, 94708.

PUBLISHED BY PACIFIC JOURNAL OF MATHEMATICS, A NON-PROFIT CORPORATION

Printed at Kokusai Bunken Insatsusha (International Academic Printing Co., Ltd.), 270, 3-chome Totsuka-cho, Shinjuku-ku, Tokyo 160, Japan.

Copyright (C) 1973 by Pacific Journal of Mathematics Manufactured and first issued in Japan 


\section{Pacific Journal of Mathematics \\ Vol. 55, No. $2 \quad$ October, 1974}

Walter Allegretto, On the equivalence of two types of oscillation for elliptic

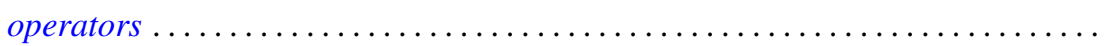

Edward Arthur Bertram, A density theorem on the number of conjugacy classes in

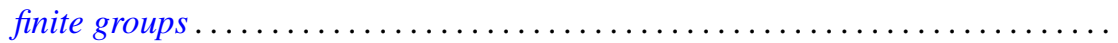

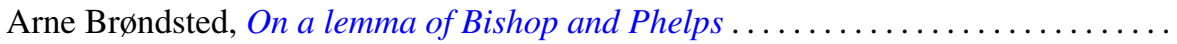

Jacob Burbea, Total positivity and reproducing kernels ..................

Ed Dubinsky, Linear Pincherle sequences . . . . . . . . . . . . . . . . . .

Benny Dan Evans, Cyclic amalgamations of residually finite groups .............

361

Barry J. Gardner and Patrick Noble Stewart, A "going down" theorem for certain

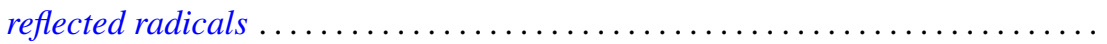

381

Jonathan Light Gross and Thomas William Tucker, Quotients of complete graphs:

revisiting the Heawood map-coloring problem ....................

Sav Roman Harasymiv, Groups of matrices acting on distribution spaces .........

Robert Winship Heath and David John Lutzer, Dugundji extension theorems for

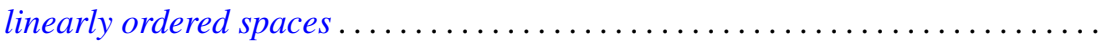

Chung-Wu Ho, Deforming p. l. homeomorphisms on a convex polygonal

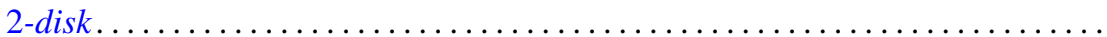

Richard Earl Hodel, Metrizability of topological spaces .................

Wilfried Imrich and Mark E. Watkins, On graphical regular representations of

cyclic extensions of groups .......................... 461

Jozef Krasinkiewicz, Remark on mappings not raising dimension of curves ..... . 479

Melven Robert Krom, Infinite games and special Baire space extensions . . . . . . 483

S. Leela, Stability of measure differential equations . . . . . . . . . . . . . . . . 489

M. H. Lim, Linear transformations on symmetric spaces . . . . . . . . . . . . . . . 499

Teng-Sun Liu, Arnoud C. M. van Rooij and Ju-Kwei Wang, On some group algebra modules related to Wiener's algebra $M_{1} \ldots \ldots \ldots \ldots \ldots \ldots \ldots \ldots \ldots \ldots \ldots$

Dale Wayne Myers, The back-and-forth isomorphism construction ............ 521

Donovan Harold Van Osdol, Extensions of sheaves of commutative algebras by

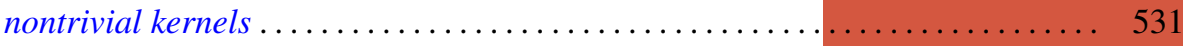

Alan Rahilly, Generalized Hall planes of even order ................... 543

Joylyn Newberry Reed, On completeness and semicompleteness of first countable

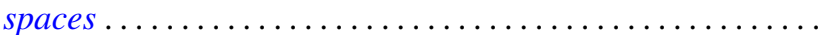

Alan Schwartz, Generalized convolutions and positive definite functions associated

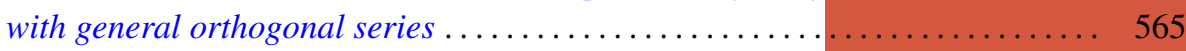

Thomas Jerome Scott, Monotonic permutations of chains . . . . . . . . . . . 583

Eivind Stensholt, An application of Steinberg's construction of twisted groups .... 595

Yasuji Takeuchi, On strongly radicial extensions . . . . ................. 619

William P. Ziemer, Some remarks on harmonic measure in space . . . . . . . . . . 629

John Grant, Corrections to: “Automorphisms definable by formulas” . . . . . . . . 639

Peter Michael Rosenthal, Corrections to: "On an inversion for the general

Mehler-Fock transform pair" ......................... 640

Carl Clifton Faith, Corrections to: "When are proper cyclics injective” . . . . . . 640 